Arq. Bras. Med. Vet. Zootec., v.67, n.6, p.1729-1734, 2015

\title{
Aminas bioativas e qualidade da carne de frangos de corte
}

\author{
[Bioactive amines and meat quality of broiler chickens] \\ D.C.S. Assis ${ }^{1}$, L.D. M. Menezes ${ }^{2}$, G.R. Silva ${ }^{1}$, J. Caccioppoli ${ }^{2}$, E.L.S. Santos ${ }^{1}$, \\ L.G.D. Heneine ${ }^{3}$, T.C. Figueiredo ${ }^{1}$, S.V. Cançado ${ }^{1}$ \\ ${ }^{1}$ Escola de Veterinária - UFMG - Belo Horizonte, MG \\ ${ }^{2}$ Instituto Mineiro de Agropecuária - IMA - Belo Horizonte, MG \\ ${ }^{3}$ Fundação Ezequiel Dias - Funed - Belo Horizonte, MG
}

\begin{abstract}
RESUMO
Com o objetivo de avaliar a qualidade da carne de frangos de corte mediante pesquisa dos níveis de aminas bioativas, foram coletadas, pelos serviços de inspeção oficiais, 160 amostras de carcaças provenientes de cinco regiões distintas do estado de Minas Gerais, durante o período de um ano. As poliaminas (espermidina e espermina) e as aminas biogênicas (putrescina, cadaverina, histamina, tiramina) foram pesquisadas por cromatografia líquida de alta eficiência e detecção ultravioleta (CLAE/UV). Os resultados encontrados demonstraram a presença das poliaminas, espermidina e espermina, em todas as amostras, em concentrações médias de $3,56 \mathrm{mg} / 100 \mathrm{~g}$ e $5,72 \mathrm{mg} / 100 \mathrm{~g}$, respectivamente. Em todas as amostras foram detectadas, em concentrações muito baixas, as aminas putrescina, cadaverina, histamina e tiramina. Foi concluído que a carne de frangos de corte produzida no estado de Minas Gerais é uma fonte de poliaminas, importantes para o crescimento e a proliferação celular, e que os baixos teores de aminas biogênicas encontrados não representam riscos à saúde do consumidor, indicando que esse tipo de carne apresenta boa qualidade, tomando por base o critério de aminas bioativas.
\end{abstract}

Palavras-chave: aminas biogênicas, poliaminas, carne de frangos de corte, CLAE-UV

\begin{abstract}
In order to evaluate the meat quality of broiler chickens by searching the bioactive amines level, 160 samples of carcass from the five regions of the Minas Gerais State, were collected during one year by the official inspection service. The poliamines (spermidine and spermine) and the biogenic amines (putrescine, cadaverine, histamine and tyramine) were determined by high performance liquid chromatography with ultraviolet detection (HPLC/UV). The results demonstrated the presence of polyamines spermidine and spermine in all samples, at mean concentrations of $3.56 \mathrm{mg} / 100 \mathrm{~g}$ and $5.72 \mathrm{mg} / 100 \mathrm{~g}$, respectively. The biogenic amines putrescine, cadaverine, histamine and tyramine were also found, but in low concentrations. It was concluded that the chicken broiler meat produced in Minas Gerais state is a source of polyamines, important for growth and cell proliferation; and that the biogenic amine levels found were low, and do not represent risks to consumer health, indicating that it has good quality, based on the criterion of bioactive amine.
\end{abstract}

Keywords: biogenic amines, polyamines, chicken broiler meat, HPLC-UV

\section{INTRODUÇÃO}

A carne de frangos de corte possui alto valor nutricional, sendo rica em proteínas, vitaminas e sais minerais. No entanto, é um produto

Recebido em 26 de maio de 2014

Aceito em 10 de junho de 2015

E-mail: deborasampaio11@gmail.com altamente perecível e que está sujeito a várias alterações, como, por exemplo, a degradação proteica. Dessa forma, tem-se buscado cada vez mais a utilização de índices que possam avaliar a qualidade desse produto e de metodologias capazes de detectar componentes tóxicos, para 
assegurar que não apresente nenhum tipo de perigo ao consumidor.

As aminas bioativas são bases orgânicas de baixo peso molecular que possuem atividade biológica. Elas podem ser classificadas em poliaminas e aminas biogênicas. As poliaminas (espermina e espermidina) estão envolvidas no crescimento e na regeneração celular por meio da regulação da função de ácidos nucleicos e da síntese de proteínas, são formadas endogenamente pelas células e também podem ser obtidas da dieta. As aminas biogênicas (histamina, serotonina, tiramina, feniletilamina, triptamina, putrescina, cadaverina e agmatina) podem ser formadas pela descarboxilação de aminoácidos por enzimas microbianas durante $\mathrm{o}$ processamento ou armazenamento de produtos alimentícios (Brink et al., 1990; Bardócz et al., 1993; Bardócz, 1995; Shalaby, 1996; Silla-Santos, 1998; Lima e Glória, 1999). Como a alta concentração das aminas biogênicas em alimentos pode ser devido à ação de enzimas descarboxilase produzidas por microrganismos, elas podem ser usadas como indicadores da qualidade dos alimentos (Silva e Glória, 2002; Balamatsia, 2006; Oliveira et al., 2009; Figueiredo et al., 2013; Rego et al., 2014). Para carne de frangos de corte, valores de aminas biogênicas maiores que $5 \mathrm{mg} / 100 \mathrm{~g}$ são indicativos de avançado estágio de deterioração (Veciana-Nogués et al., 1997).

Como a superfície da carcaça de frangos de corte e da carne oferece condições adequadas para o desenvolvimento de microrganismos e, consequentemente, para a produção de aminas bioativas, o objetivo deste trabalho foi avaliar a qualidade da carne de frangos de corte produzida no estado de Minas Gerais, mediante pesquisa dos níveis de aminas bioativas (putrescina, cadaverina, histamina, tiramina, espermidina e espermina).

\section{MATERIAL E MÉTODOS}

Para maior representatividade da amostragem, o estado de Minas Gerais foi dividido em 12 mesorregiões, de acordo com o Instituto Brasileiro de Geografia e Estatística (IBGE). Determinadas as mesorregiões, foi verificado em quais delas existiam estabelecimentos fiscalizados pelo Serviço de Inspeção Federal (SIF) e pelo Serviço de Inspeção Estadual (SIE). Após esse procedimento, os estabelecimentos foram numerados e sorteados aleatoriamente, por mesorregião (Campo das Vertentes, Metropolitana, Oeste de Minas, Sul e Sudoeste e Triângulo Mineiro) e por sistema de inspeção. Em cada mesorregião, foram coletadas amostras de um estabelecimento registrado no SIF e de um no SIE, totalizando 10 estabelecimentos avaliados no estado.

De cada estabelecimento, foram encaminhadas para análise quatro amostras de quatro lotes distintos de produção por coleta. Foram realizadas quatro coletas no período de um ano (uma coleta por trimestre), totalizando 160 amostras. De acordo com a característica de comercialização do estabelecimento, as carcaças de frangos foram coletadas congeladas (96 carcaças provenientes de três indústrias sob inspeção federal e três indústrias sob inspeção estadual) ou resfriadas (64 carcaças provenientes de duas indústrias sob inspeção federal e duas indústrias sob inspeção estadual). Para a realização das análises de aminas bioativas, foi utilizada a carne do peito.

As aminas bioativas foram separadas por cromatografia líquida de alta eficiência (CLAE) por pareamento de íons em coluna de fase reversa e quantificadas por detecção ultravioleta (UV) após derivação pré-coluna com cloreto de dansila. Os padrões de aminas utilizados foram dicloridrato de putrescina, dicloridrato de cadaverina, cloridrato de tiramina, dicloridrato de histamina, tricloridrato de espermidina e tetracloridrato de espermina (Sigma Chemical Co., St Louis, MO, EUA). Todos os reagentes utilizados nas análises foram de grau puro para análise (p.a.), exceto os solventes utilizados para cromatografia, que foram de grau cromatográfico.

Para realização do procedimento de extração, foram coletados aproximadamente $10 \mathrm{~g}$ de carne de peito de frango, que foram triturados utilizando um mixer (Arno S.A. Indústria e Comércio, São Paulo, Brasil). Após a trituração, foram pesados $5 \mathrm{~g}$ da amostra em tubos de centrífuga de polipropileno de $50 \mathrm{~mL}$, aos quais foram adicionados $7 \mathrm{~mL}$ de ácido tricloroacético (TCA) a 5\%. Após a adição de TCA 5\%, os tubos foram agitados por 10 minutos em mesa agitadora a 200rpm (Tecnal, São Paulo, Brasil) e depois centrifugados a $5.232 \mathrm{xg}$ a $4^{\circ} \mathrm{C}$ por 25 minutos, em centrífuga refrigerada (Cientec, São 
Paulo, Brasil). Após a primeira etapa de centrifugação, o sobrenadante foi filtrado em papel de filtro qualitativo. Esta etapa foi repetida por mais duas vezes, com adições de $7 \mathrm{~mL}$ e $6 \mathrm{~mL}$ de TCA $5 \%$, totalizando $20 \mathrm{~mL}$ de ácido adicionado em três etapas sucessivas de extração $(7 \mathrm{~mL}, 7 \mathrm{~mL}$ e $6 \mathrm{~mL})$. Os extratos obtidos foram armazenados em microtubos de $0,5 \mathrm{~mL}$ e congelados a $-20^{\circ} \mathrm{C}$ para posterior realização do processo de derivação e análise cromatográfica.

Para o processo de derivação, $200 \mu \mathrm{L}$ do extrato foram transferidos para tubos de centrífuga de polipropileno, aos quais foram adicionados $400 \mu \mathrm{L}$ de solução saturada de bicarbonato de sódio e $800 \mu \mathrm{L}$ de solução de cloreto de dansila $\left(\mathrm{C}_{12} \mathrm{H}_{12} \mathrm{ClNO}_{2} \mathrm{~S}\right)$. A solução foi agitada em vortex por aproximadamente 30 segundos e deixada ao abrigo da luz em banho de água quente a $60^{\circ} \mathrm{C}$, por cinco minutos. Após essa etapa, $200 \mu \mathrm{L}$ de L-Prolina foram adicionados à solução, que foi agitada novamente em vortex por 30 segundos e armazenada ao abrigo da luz à temperatura ambiente, por 30 minutos. Decorrido esse tempo, foram adicionados $1.000 \mu \mathrm{L}$ de tolueno à solução, que foi agitada em vortex por um minuto para posterior centrifugação a $4.350 \mathrm{xg}$ por 10 minutos à temperatura de $4^{\circ} \mathrm{C}$, para a separação das fases. A fase orgânica (sobrenadante) foi recuperada com auxílio de um pipetador automático para um tubo de ensaio de $5 \mathrm{~mL}$ e levada ao concentrador de amostras para evaporação por adição de fluxo de nitrogênio por 10 minutos a uma temperatura de $60^{\circ} \mathrm{C}$.

O extrato obtido foi dissolvido com $600 \mu \mathrm{L}$ de acetonitrila grau UV/CLAE (Merck, Darmstadt, Alemanha) e filtrado com unidade filtrante com membrana de PTFE, poro $0,45 \mu \mathrm{m}$ e diâmetro de 13 a $15 \mathrm{~mm}$ (Millipore Corp, Milford, MA,
EUA), sendo o filtrado reservado para injeção. As etapas de derivação e as condições cromatográficas foram validadas por Assis (2014). O limite de detecção do método foi de $0,03 \mathrm{mg} / 100 \mathrm{~g}$, e o limite de quantificação de $0,09 \mathrm{mg} / 100 \mathrm{~g}$.

O ensaio foi conduzido no delineamento inteiramente ao acaso (DIC), em arranjo fatorial $10 \times 4$ (10 estabelecimentos x quatro períodos de amostragem). Em cada período de amostragem e em cada estabelecimento, foram coletadas quatro carcaças de frangos de corte de lotes distintos de produção (cada carcaça foi considerada uma repetição). Para a avaliação dos dados obtidos, foi realizada a transformação de dados, e os resultados foram avaliados utilizando-se o teste de Kruskall-Wallis, em nível de significância de $5 \%$.

\section{RESULTADOS E DISCUSSÃO}

Os resultados das análises da pesquisa das aminas bioativas na carne de peito de frangos de corte encontram-se na Tab. 1. Em todas as 160 amostras avaliadas, foi observada a presença de espermidina e de espermina em concentrações superiores ao limite de quantificação do método $(0,09 \mathrm{mg} / 100 \mathrm{~g})$. A putrescina e a cadaverina foram detectadas em $126(78,75 \%)$ amostras; a putrescina foi quantificada em $118(93,65 \%)$, enquanto a cadaverina em 109 (86,5\%). A histamina foi encontrada em 130 amostras $(81,25 \%)$, mas apenas 63 dessas $(48,46 \%)$ estavam acima do limite de quantificação do método, e a tiramina foi detectada em 78 $(48,75 \%)$ amostras, mas só pôde ser quantificada em $54(69,23 \%)$.

Tabela 1. Resultados das análises de aminas bioativas em carne de peito de frango, produzida no estado de Minas Gerais, de acordo com os limites de detecção e quantificação do método

\begin{tabular}{lccc}
\hline Amina & ND & Abaixo do LQ & Quantificadas \\
\hline Putrescina & 34 & 8 & 118 \\
Cadaverina & 34 & 17 & 109 \\
Histamina & 30 & 67 & 63 \\
Tiramina & 82 & 24 & 54 \\
Espermidina & 0 & 0 & 160 \\
Espermina & 0 & 0 & 160 \\
\hline
\end{tabular}

ND: não detectado = abaixo do limite de detecção (LD) do método (LD $=<0,03 \mathrm{mg} / 100 \mathrm{~g})$.

LQ: limite de quantificação do método de cada amina (LQ $=0,09 \mathrm{mg} / 100 \mathrm{~g})$. 
Não foram observadas diferenças significativas $(\mathrm{P}>0,05)$ nos níveis das aminas bioativas estudadas em relação ao sistema de inspeção (SIF ou SIE) e à temperatura de comercialização da carcaça (congelada ou resfriada) em nenhuma das mesorregiões avaliadas.

Os resultados das pesquisas das poliaminas espermidina e espermina estão descritos na Tab. 2. Não houve diferença significativa $(P>0,05)$ nas concentrações das poliaminas entre as mesorregiões do estado de Minas Gerais. As poliaminas espermidina e espermina podem ser formadas endogenamente pelas células, e entre suas funções biológicas estão a participação no crescimento e na proliferação celular, por meio da regulação da função de ácidos nucleicos, e a síntese de proteínas (Bardócz, 1995; Kalač e Krausová, 2005; Moinard et al., 2005). Dessa maneira, os requisitos de poliaminas são maiores durante os períodos de intenso crescimento, o que pode explicar sua presença na carne de frangos de corte, que é um produto rico em nutrientes.

Resultados similares da pesquisa de espermidina foram obtidos por Moreira et al. (2008), que observaram a concentração média de $2,74 \mathrm{mg} / 100 \mathrm{~g}$ em carne de peito de frango maturada. No entanto, Silva e Glória (2002) e Balamatsia et al. (2006), ao trabalharem com amostras de carne de frangos de corte, encontraram concentrações inferiores às observadas neste trabalho. Em relação à espermina, os teores encontrados foram similares aos observados por Balamatsia et al. (2006), que verificaram a concentração de $5,33 \mathrm{mg} / 100 \mathrm{~g}$ em carne de peito de frango refrigerada.

Tabela 2. Conteúdo de poliaminas $(\mathrm{mg} / 100 \mathrm{~g})$ encontrado na carne de peito de frangos de corte produzida no estado de Minas Gerais

\begin{tabular}{lcc}
\hline Mesorregião & Espermidina & Espermina \\
\hline Sul e Sudoeste & 3,296 & 5,788 \\
Campo das Vertentes & 3,051 & 5,701 \\
Oeste de Minas & 3,678 & 5,902 \\
Metropolitana & 3,457 & 5,859 \\
Triângulo Mineiro & 4,305 & 5,353 \\
\hline
\end{tabular}

Os altos teores de espermidina e espermina encontrados na carne de peito de frango demonstram a importância nutricional desta como fonte de poliaminas desejáveis na dieta. No entanto, a ingestão diária máxima de poliaminas recomendada, de 50,8 a $79,9 \mathrm{mg}$ de espermidina e de 70,8 a $111,3 \mathrm{mg}$ de espermina, deve ser respeitada para que não haja prejuízo à saúde (Bardócz et al., 1993).

De forma semelhante às poliaminas, não foi observada diferença significativa $(\mathrm{P}>0,05)$ nas concentrações das aminas biogênicas encontradas na carne de peito de frango de corte produzida nas diferentes mesorregiões do estado de Minas Gerais (Tab. 3).

Tabela 3. Médias dos teores de aminas biogênicas $(\mathrm{mg} / 100 \mathrm{~g})$ encontrados na carne de peito de frango produzida no estado de Minas Gerais

\begin{tabular}{lcccc}
\hline Mesorregião & Putrescina & Cadaverina & Histamina & Tiramina \\
\hline Sul e Sudoeste & 0,28 & 1,15 & 0,14 & 0,25 \\
Campo das Vertentes & 0,27 & 0,96 & 0,06 & 0,11 \\
Oeste de Minas & 0,26 & 1,08 & 0,09 & 0,18 \\
Metropolitana & 0,28 & 0,56 & 0,08 & 0,07 \\
Triângulo Mineiro & 0,19 & 0,74 & 0,07 & 0,05 \\
\hline
\end{tabular}

As aminas putrescina e cadaverina foram detectadas, em baixas concentrações, em todas as mesorregiões do estado. O conteúdo dessas aminas biogênicas em alimentos aumenta devido à atividade bacteriana durante o seu processamento e armazenamento inadequados (Kalač e Krausová, 2005). O emprego de temperaturas de refrigeração ou congelamento, como forma de conservação dos alimentos, assume um papel fundamental, especialmente para a carne de frango, que é um produto altamente perecível.

As concentrações de putrescina encontradas no presente trabalho foram inferiores às observadas por Lázaro et al. (2013), que detectaram teores médios de putrescina de $0,68 \mathrm{mg} / 100 \mathrm{~g}$ em carne de peito de frango. No entanto, em relação à 
cadaverina, esse mesmo autor encontrou resultados médios de $0,531 \mathrm{mg} / 100 \mathrm{~g}$ de amostra, similares aos observados neste trabalho.

Apesar de serem mais comuns os relatos de intoxicação por histamina e tiramina em alimentos e de a maior ênfase ser dada à detecção dessas aminas, a pesquisa tanto de putrescina quanto de cadaverina também é importante, pois, segundo Shalaby (1996), em concentrações elevadas, elas podem levar à hipotensão, bradicardia, contração exagerada dos músculos da mandíbula, paralisia das extremidades e potencialização da toxicidade de outras aminas.

As aminas histamina e tiramina também foram detectadas, em muito baixas concentrações, em todas as mesorregiões do estado. A importância da pesquisa de histamina e tiramina em alimentos reside no fato de já terem sido descritos vários casos de intoxicações e reações alérgicas de caráter agudo provocadas por essas aminas. Valores baixos destas são capazes de causar agravo à saúde, dependendo da susceptibilidade do indivíduo (Brink et al., 1990).

Os teores de histamina encontrados na carne de peito de frango foram próximos aos observados por Silva e Glória (2002), que detectaram, em carne de coxa de frango refrigerada $\left(4 \pm 1^{\circ} \mathrm{C}\right)$, a concentração de $0,07 \mathrm{mg} / 100 \mathrm{~g}$. Em relação à tiramina, os valores encontrados foram semelhantes aos verificados por Moreira et al. (2008), que observaram a concentração de $0,095 \mathrm{mg} / 100 \mathrm{~g}$ dessa amina em amostras de carne de peito de frango maturadas. No entanto, Lázaro et al. (2013) encontraram valores elevados de tiramina em amostras de carne de peito de frango embaladas em bandejas de poliestireno $(23,07 \mathrm{mg} / 100 \mathrm{~g})$ e em sacos de polietileno $(19,54 \mathrm{mg} / 100 \mathrm{~g})$.

As poliaminas obtidas da dieta são importantes para o funcionamento de órgãos com altas taxas de reposição celular, como o trato gastrointestinal, o pâncreas e o baço. As aminas biogênicas são metabólitos da atividade microbiana e podem ser utilizadas como índices de qualidade dos alimentos, refletindo a qualidade da matéria-prima e as condições de processamento.

De acordo com o índice de qualidade química, proposto por Veciana-Nogués et al. (1997), o somatório dos valores das aminas putrescina, cadaverina, histamina e tiramina superior a $5 \mathrm{mg} / 100 \mathrm{~g}$ indica estágio de deterioração do alimento. Os resultados dos níveis de aminas biogênicas encontrados nesta pesquisa foram menores que o índice de qualidade apresentado e demonstraram que as carnes de frangos de corte produzidas nas diversas mesorregiões do estado de Minas Gerais possuíam boa qualidade.

\section{CONCLUSÕES}

Foi concluído que a carne de frangos de corte produzida no estado de Minas Gerais é uma fonte de poliaminas, importantes para o crescimento e a proliferação celular e que os baixos teores de aminas biogênicas, formadas pela descarboxilação de aminoácidos por enzimas bacterianas, não representam riscos à saúde do consumidor, indicando que esse tipo de carne apresenta boa qualidade, tomando por base o critério de aminas bioativas.

\section{AGRADECIMENTOS}

Os autores agradecem a assistência do Colegiado de Pós-Graduação em Ciência Animal da Escola de Veterinária, por prover fundos para a publicação, e o auxílio do Conselho Nacional de Desenvolvimento Científico e Tecnológico $(\mathrm{CNPq})$, por prover fundos para $\mathrm{O}$ desenvolvimento desta pesquisa e de bolsa de estudo. Os autores agradecem também ao Laboratório de Segurança Microbiológica em Alimentos (LSMA) do Instituto Mineiro de Agropecuária (IMA) e ao Laboratório de Imunologia Aplicada, da Fundação Ezequiel Dias (Funed), por viabilizarem as análises realizadas neste projeto. 


\section{REFERÊNCIAS}

ASSIS, D.C.S. Aminas bioativas em carne de peito de frango e em ovos de consumo produzidos no estado de Minas Gerais. 2014. 80f. Dissertação (Mestrado em Ciência Animal) Escola de Veterinária, Universidade Federal de Minas Gerais, Belo Horizonte, MG.

BALAMATSIA, C.C.; PAEOLOGOS, E.K.; KONTOMINAS, M.G. et al. Correlation between microbial flora, sensory changes and biogenic amines formation in fresh chicken meat stored aerobically or under modified atmosphere packaging at $4^{\circ} \mathrm{C}$ : possible role of biogenic amines in spoilage indicators. Antonie Leewenhoek, v.89, p.9-17, 2006.

BARDÓCZ, S.; GRANT, G.; BROWN, D.S. et al. Polyamines in food: implications for growth and health. J. Nutr. Biochem., v.4, p.66-71; 1993.

BARDÓCZ, S. Polyamines in food and their consequences for food quality and human health. Trends Food Sci. Technol., v.6, p.341-346, 1995.

BRINK, B.T.; DAMINK, C.; JOOSTEN, H.M.L.J. et al. H. Occurrence and formation of biologically active amines in foods. Int. J. Food Microbiol., v.11, p.73-84, 1990.

FIGUEIREDO, T.C.; VIEGAS, R.P.; LARA, L.J. C. et al. Bioactive amines and internal quality of commercial eggs. Poult. Sci., v.92, p.1376-1384, 2013.

KALAČ, P.; KRAUSOVÁ, P. A review of dietary polyamines: formation, implications for growth and health and occurrence in foods. Food Chem., v.90, p.219-230, 2005.

LÁZARO, C.A.; CONTE-JÚNIOR, C.A.; CUNHA, F.L. et al. Validation of an HPLC methodology for the identification and quantification of biogenic amines in chicken meat. Food Anal. Methods, v.6, p.1024-1032, 2013.

LIMA, A.S.; GLÓRIA, M.B.A. Aminas bioativas em alimentos. Bol. Soc. Bras. Ciênc. Tecnol. Aliment., v.33, p. 70-79, 1999.
MIN, J.S.; LEE, S.O.; JANG, A. et al. Control of microorganisms and reduction of biogenic amines in chicken breast and thigh by irradiation and organic acids. Poult. Sci., v.86, p.20342041, 2007.

MOINARD, C.; CYNOBER, L.; BANDT, J.P. Polyamines: metabolism and implications in human diseases. Clin. Nutr., v.24, p.184 -197, 2005.

MOREIRA, A.P.S.; GIOMBELLI, A., LABANCA, R.A. et al. Effect of aging on bioactive amines, microbial flora, physicochemical characteristics, and tenderness of broiler breast meat. Poult. Sci., v.87, p.18681873, 2008.

OLIVEIRA, G.E.; FIGUEIREDO, T.C.; SOUZA, M.R. et al. Bioactive amines and quality of egg from Dekalb hens under different storage conditions. Poult. Sci., v.88, p.24282434, 2009.

REGO, I.O.P.; MENEZES, L.D.M.; FIGUEIREDO, T.C. Bioactive amines and microbiological quality in pasteurized and refrigerated liquid whole egg. Poult. Sci., v.93, p.1018-1022, 2014

SHALABY, A.R. Significance of biogenic amines to food safety and human health. Food Res. Int., v.29, p.675-690, 1996.

SILLA-SANTOS, M.H. Amino acid decarboxylase capability of microorganisms isolated in Spanish fermented meat products. Int. J. Food Microbiol., v.39, p.227-230, 1998.

SILVA, C.M.G.; GLÓRIA, M.B.A. Bioactive amines in chicken breast and thigh after slaughter and during storage at $4^{\circ} \mathrm{C}$ and in chicken-based meat products. Food Chem., v.78, p.241-248, 2002.

VECIANA-NOGUÉS, M.T.; MARINE-FONT, A.; VIDAL-CAROU, M.C. Biogenic amines as hygienic quality indicators of tuna. Relationships with microbial counts, ATP-related compounds, volatile amines, and organoleptic changes. $J$. Agric. Food Chem., v.45, p.2036-2041, 1997. 